\title{
Nitric oxide synthase expression correlates with death in an experimental mouse model of dengue with CNS involvement
}

Kátia Paulino Ribeiro de Souza', Emanuele Guimarães Silva', Eliseu Soares de Oliveira Rocha', Leandra Barcelos Figueiredo ', Camila Megale de Almeida-Leite', Rosa Maria Esteves Arantes ${ }^{1}$, Juliana de Assis Silva Gomes ${ }^{1}$, Gustavo Portela Ferreira², Jaquelline Germano de Oliveira ${ }^{3}$, Erna Geessien Kroon ${ }^{1+}$ and Marco Antônio Campos ${ }^{3 * \dagger}$

\begin{abstract}
Background: The clinical presentation of dengue is classified by the World Health Organization into dengue without warning signs, dengue with warning signs and severe dengue. Reports of neurological disease caused by Dengue virus (DENV) are becoming frequent, with symptoms that include reduced consciousness, severe headache, neck stiffness, focal neurological signs, tense fontanelle and convulsions. However, the immune mechanisms involved in neurovirulence remain poorly understood. Here we present a mouse model in which one genotype of DENV is inoculated by the intracranial route and infects C57/BL6 mice and replicates in the brain, causing death of mice.

Methods: Mice were infected with different serotypes/genotypes of DENV by the intracranial route to evaluate viral replication, host cytokine and nitric oxide synthase 2 (Nos2) expression in the brain via real-time PCR. Histological analysis of the brain tissues was also performed. An analysis of which cells were responsible for the expression of cytokines and Nos 2 was performed using flow cytometry. Survival curves of infected animals were also generated.

Results: DENV 3 genotype I infected mice and replicated in the brain, causing death in our murine model. The increased levels of NOS2 could be the cause of the death of infected mice, as viral replication correlates with increased Nos2 and cytokine expression in the brain of C57BL/6 mice. In Nos2 ${ }^{-1-}$ mice that were infected with DENV, no clinical signs of infection were observed and cytokines were expressed at low levels, with the exception of interferon gamma (Ifng). Additionally, the Ifng ${ }^{-1-}$ mice infected with DENV exhibited a severe and lethal disease, similar to the disease observed in C57BL/6 mice, while the DENV- infected Nos $2^{-1-}$ mice did not display increased mortality. Analyses of the brains from infected C57BL/6 mice revealed neuronal degeneration and necrosis during histopathologic examination. IFNg and NOS2 were produced in the brains of infected mice by CD4 ${ }^{+} \mathrm{T}$ cells and macrophages, respectively.
\end{abstract}

Conclusion: The neurovirulence of DENV 3 genotype I is associated with a deleterious role of NOS2 in the brain, confirming this murine model as an appropriate tool to study DENV neurovirulence.

Keywords: Dengue virus, Murine model, Neurovirulence, Neuropathogenesis, Immunopathogenesis, Encephalitis, Nitric oxide synthase 2, Nitric oxide, Interferon gamma

\footnotetext{
*Correspondence: marcoasc@cpqrr.fiocruz.br

${ }^{\dagger}$ Equal contributors

${ }^{3}$ Centro de Pesquisas René Rachou, Fundação Oswaldo Cruz, Belo Horizonte,

Minas Gerais, Brazil

Full list of author information is available at the end of the article
} 


\section{Background}

The clinical signs of neurological disease caused by Dengue virus (DENV) are reduced consciousness, severe headache, neck stiffness, focal neurological signs, tense fontanelle, and convulsions [1]. The pathophysiology of neurological involvement in dengue infection is attributed to several factors, including cerebral edema, cerebral hemorrhage, cerebral anoxia, microcapillary hemorrhage, and the release of toxic products [2]. Therefore, dengue infection is considered to be a cause of encephalitis and other neurological manifestations in endemic regions [1,3-12]. Studies have shown that DENV can interact with various cell types including dendritic cells, monocytes, macrophages, hepatocytes and endothelial cells [13], resulting in the production of immune mediators that are present during severe DENV infection. High levels of cytokines, such as TNF alpha (TNFa), IFN gamma (IFNg) [14,15], have been detected in patients with severe dengue. However, it is still not clear how these cytokines are induced or what these cytokines' role is in dengue pathogenesis. Despite many in vivo and in vitro studies that have attempted to determine the role of various cytokines [9,13,16-18], the lack of small animal models that simulate dengue human symptoms limits the dissection of the mechanisms of dengue pathogenesis [11].

Previous work in our laboratory identified DENV-3 genotype I in serum samples from patients in Minas Gerais classified as having severe dengue; subsequently, the same genotype was found in naturally infected fieldcaught Aedes aegypti mosquitoes and eggs [19,20]. We previously reported the virulence of low-passage isolates of DENV-3 genotypes I and III isolated from Brazil in C57BL/6 mice inoculated by the intracranial (i.c.) route. We observed that the DENV-3 genotype I isolate caused neurological disease, whereas infection with the DENV3 genotype III isolate was asymptomatic [21].

To better characterize and understand the immunopathology and neurovirulence that occurs in dengue infected hosts, we used DENV-3 genotype I isolates obtained from fatal human dengue cases (here named MG20 and MG21) to experimentally infect mice in this study, causing a dose-dependent fatal neurological disease. We also demonstrated that after i.c. inoculation, the virus isolate MG20 DENV-3 genotype I induced higher levels of expression of cytokines and proinflammatory mediators including nitric oxide synthase (NOS2) in the brain. We showed that this virus had reduced neurovirulence in $N o s 2^{-1-}$ mice. The mortality of $\operatorname{Nos} 2^{-/-}$mice infected with this dengue isolates was reduced to zero, in contrast with the mortality of the immunocompetent C57BL/6 mice and interferon gamma $(\text { Ifng })^{-1-}$ mice, which were $80 \%$ and $100 \%$, respectively. These results indicated a correlation between immunopathology and Nos2 expression in the brain when infection with a neurovirulent virus occurs. Therefore, this murine model can be used as a tool to study dengue neurovirulence.

\section{Methods}

Virus

Dengue virus (DENV-1, BH4); DENV-2 (Pi59); DENV-3 (MG20); DENV-3 (MG21) and DENV-3 (Pi76) isolates from the sera of dengue patients were obtained from the collection of the Laboratório de Virus, UFMG and passaged no more than 6 times in C6/36 cells. DENV-1 Mochizuki [22] was kindly provided by Prof. Luiz Tadeu Figueiredo, USP, SP, Brazil, and DENV-4 (Boa Vista, 1982) [23] was provided by Prof. Mauricio Lacerda Nogueira, FAMERP, USP, SP, Brazil. Viral stocks were generated in C6/36 cells infected at a multiplicity of infection (moi) of 0.01 . To produce viral stocks, the supernatant was harvested, cell debris was removed by centrifugation at $2,000 \times \mathrm{g}$ for $5 \mathrm{~min}$, and the viral supernatant was stored at $-70^{\circ} \mathrm{C}$.

\section{Cells}

C6/36 cells (American Type Culture Collection, Manassas, VA) were maintained in Leibowitz (L-15) medium (Gibco, USA) supplemented with $5 \%$ heat-inactivated fetal bovine serum (Cultilab, Brazil) and antibiotics in an incubator at $28^{\circ} \mathrm{C}$. These cells were used to support virus replication.

BHK-21 cells (American Type Culture Collection, Manassas, VA) were maintained in minimal essential medium (Gibco, USA) supplemented with $5 \%$ heatinactivated fetal bovine serum (Cultilab, Brazil) and antibiotics in $5 \% \mathrm{CO}_{2}$ at $37^{\circ} \mathrm{C}$. These cells were used for virus titration.

\section{Mice}

All of the animal experiments were approved based on the regulations and guidelines of the Ethical and Animal Use Committee on Animal Experimentation (CETEA/ UFMG 026/2011).

C57BL/6 (WT) mice were obtained from Centro de Bioterismo-Universidade Federal de Minas Gerais (MG, Brazil). The Nos $2^{-/-}$and Ifng $g^{-1-}$ mice on the C57BL/6 background were obtained from Centro de Criação de Animais de Laboratório-Fundação Oswaldo Cruz (RJ, Brazil). Male mice at $8-10$ weeks of age were inoculated via the intracranial route with $20 \mu \mathrm{L}$ of the virus or uninfected C6/36 cell supernatants as a control. The mice were anesthetized using ketamine (Agribrands do Brasil Ltda, Brazil).

\section{Plaque reduction neutralization test $\left(\mathrm{PRNT}_{50}\right.$ )}

The plaque assay in BHK-21 cells was performed using a protocol that was modified from Russell and others (1967) [24]. Briefly, BHK-21 cells were seeded into 24well plates at a density of $1 \times 10^{5}$ cells/well and incubated overnight at $37^{\circ} \mathrm{C}$ in $5 \% \mathrm{CO}_{2}$ until the cells were 
approximately $80 \%$ to $90 \%$ confluent. Serum samples were inactivated at $56^{\circ} \mathrm{C}$ for $30 \mathrm{~min}$ and serially diluted in 2-fold steps (1:20 to 1:120), and the virus (containing 40-60 pfu of DENV-3) was preincubated with the sera in a final volume of $360 \mu \mathrm{L}$ for $1 \mathrm{~h}$ at room temperature. The cell monolayer was washed with PBS, and $150 \mu \mathrm{L}$ of the virus and serum mixture was added to the cells for $1 \mathrm{~h}$ at $37^{\circ} \mathrm{C}$ and overlaid with $1 \mathrm{ml}$ per well of MEM containing 1.5\% FBS, 1.5\% carboxymethyl cellulose (Sigma-Aldrich, USA) and antibiotics. The plates were incubated for 5 days at $37^{\circ} \mathrm{C}$ in $5 \% \mathrm{CO}_{2}$. Controls were included, and the test was performed in duplicate. The cells were fixed with $4 \%$ formalin for 1 hour and stained with $0.8 \%$ crystal violet (Sigma-Aldrich, USA) for $15 \mathrm{~min}$. The plaque counts were averaged and are presented in Units per ml, which corresponds to the reciprocal of the dilution that neutralized 50 percent of the plates in $1 \mathrm{ml}$ serum.

\section{RNA extraction}

The brains were aseptically removed from mice and stored at $-70^{\circ} \mathrm{C}$ until processing. RNA extraction was performed using the TRIzol reagent (Invitrogen) according to the manufacturer's instructions. The extracted RNA was quantified with a Nanodrop ND-1000 spectrophotometer (Thermo Scientific) at 260 and $280 \mathrm{~nm}$.

\section{Reverse transcription}

Reverse transcription was performed according to the procedures provided by the manufacturer of the M-MLV RT enzyme (Promega, Madison, WI) using $3 \mu \mathrm{g}$ of RNA.

\section{Real-time PCR}

Real-time PCR [25] was performed to measure the mRNA expression levels of cytokines, chemokines and Nos 2 and to measure the 5'UTR genomic region of DENV in the indicated mice. The reactions were performed using the SYBR Green PCR Master Mix (Applied Biosystems, Carlsbad, CA) in a Step One real-time PCR System and the reaction conditions were $50^{\circ} \mathrm{C}$ for 2 minutes, $95^{\circ} \mathrm{C}$ for 10 minutes, and 40 cycles of $95^{\circ} \mathrm{C}$ for 15 minutes and $60^{\circ} \mathrm{C}$ for 1 minute, followed by a final dissociation stage. The following oligonucleotides were used in the reactions: Hypoxanthine-guanine phosphoribosyl transferase (Hprt) (forward: 5'-GTTGGATACAGGCCAGACTTTGTTG-3'; reverse: 5'-GATTCAACTTGCGCTCATCTTAGGC-3'); Ifnb (forward: 5'-CTGGAGCAGCTGAATGGAAA-3'; reverse: 5'-GTCTGCTGGTGGAGTTCAT-3'); Cxcl10 (forward: 5'-GCCGTCATTTTCTGCCTCAT-3'; reverse: 5'-G CTTCCCTATGGCCCTCATT-3'); Ccl2 (forward: 5'-CTT CTGGGCCTGCTGTTCA-3'; reverse: 5'-CCAGCCTACT CATTGGGATCA-3'); Ccl3 (forward: 5'-ACTGCCTGCT GCTTCTCCTA-3'; reverse: 5'-TTGGAGTCAGCGCAGA TCTG-3'); Il1b (forward: 5'-CGCAGCAGCACATCAA CAAGAGC-3'; reverse: 5'-TGTCCTCATCCTGGAAGG
TCCACG-3'); Ifng (forward: 5'- TCAAGTGGCATAGAT GTGGAAGAA-3'; reverse: 5'- TGGCTCTGCAGGATTT TCATG-3'); Tnfa (forward: 5'- CATCTTCTCAAAATTC GAGTGACAA-3'; reverse: 5'- TGGGAGTAGACAAGGT ACAACCC-3'); Ccl5 (forward: 5'- GCAAGTGCTCCAA TCTTGCA-3'; reverse: 5'- CTTCTCTGGGTTGGCACA CA-3'); Nos2 (forward: 5'- CAGCTGGGCTGTACAAAC CTT-3'; reverse: 5' - CATTGGAAGTGAAGCGTTTCG-3'); and 5'UTR region of DENV (forward: 5'- TCGGAAGC TTGCTTAACGTAG-3'; and reverse: 5'- TCCGTTGGTT GTTCATCAGA-3'). The relative quantification methodology was used to analyze the data. Gene or viral RNA expression was normalized to the expression level of the constitutively expressed gene Hprt. All reactions were replicated.

\section{Cell preparation and flow cytometry}

On the 8th day post infection (d.p.i.), mice were anesthetized and perfused with phosphate-buffered saline (PBS). Brains were removed and the adherent leukocytes were isolated using a previously described protocol [26]. Aliquots of these leukocytes were incubated with APClabeled anti-mouse F4/80 (eBioscience, USA) to identify macrophages, FITC-labeled anti-mouse NK1.1 (BD Pharmingen, USA) to identify NK cells, APC-labeled antimouse CD4 (eBioscience, USA) to identify helper T cells, and PECy5-labeled anti-mouse CD8 (BD Pharmingen, USA) to identify cytotoxic T cells. The cells were washed and fixed with FACS FIX Solution (BD Pharmingen, USA). After fixation the leukocytes were washed twice and submitted to permeabilization by the addition of $150 \mu \mathrm{L}$ of Perm buffer (FACS buffer supplemented with $0.5 \%$ saponin, Sigma-Aldrich, USA) for $10 \mathrm{~min}$. at room temperature. The leukocytes were then incubated with $20 \mu \mathrm{L}$ of PE-labeled anti-IFNg and FITC-labeled anti-NOS2 (BD Pharmingen, USA) for 15 minutes at $4^{\circ} \mathrm{C}$ in the dark. After two wash steps, the cells were fixed with FACS FIX Solution and stored at $4^{\circ} \mathrm{C}$ for cytometric acquisition. One hundred thousand events were acquired for each sample. A FACS Calibur (Becton Dickinson, CA, USA) with CellQuest $^{\text {tw }}$ software was used for acquisition and the data were analyzed using the Flowjo 7.2.5 software (Tree Star, Inc., Ashland, OR) and are presented as the percentage of positive cells within the gated population.

\section{Histological analysis}

Brain fragments were fixed in 10\% neutral-buffered formalin and processed for paraffin embedding. The brain sagittal sections $(4 \mu \mathrm{m})$ were stained with hematoxylin and eosin (H\&E). The images were acquired using an Olympus BX51 microscope and the Image-Pro Express 4.0 (Media Cybernetics, MD, USA) software. 


\section{Morphometric analysis}

Twelve images per specimen were obtained, and perivascular inflammatory areas, which are areas of increased cellularity in the parenchyma immediately close to a small vessel, were manually measured using the Image J $1.45 \mathrm{~S}$ software (NIH, USA), and expressed as the inflammatory area per $100 \mu \mathrm{m}^{2}$ of brain tissue. Data from the different groups were compared with one-way analysis of variance (ANOVA) (GraphPad Prism software; San Diego, USA). Statistical significance was set at $\mathrm{P}<0.05$ when comparing the data from the 8th d.p.i. in C57BL/6 mice with all of the other bars.

\section{Statistical analysis}

Real-time PCR was statistically analyzed using the Kruskal-Wallis nonparametric tests and Dunn's multiple comparison tests. Kaplan-Meier survival curves were used to display the survival data, and log rank analyses were employed to determine the statistical significance between the experimental groups. To analyze flow cytometry results, nonparametric two-way ANOVA tests and the Bonferroni post-hoc test were performed. The analyses were conducted using GraphPad Prism 5 software for Windows (GraphPad Software, Inc., La Jolla, CA).

\section{Results}

Nitric oxide synthase expression correlates with death in a mouse experimental model of dengue with CNS involvement

C57BL/6 (WT) mice were i.c. inoculated with concentrations from $4 \times 10$ to $4 \times 10^{3}$ pfu of low-passage isolates of DENV-1 (BH4); DENV-2 (Pi59); DENV-4 (Boa Vista, 1982), DENV-3 genotype I (MG20), DENV-3 genotype I (MG21), or DENV-3 genotype III (Pi76). The mice were monitored daily to determine their susceptibility to infection and to observe clinical signs of infection such as weight loss, lethargy, ruffled fur and a hunched posture. Inoculation of mice with uninfected C6/36 cell supernatants were used as controls. Only DENV-3 genotype I (MG20 and MG21)-infected mice exhibited clinical signs and mortality when doses of $4 \times 10^{3}$ pfu (100\% mortality) or $4 \times 10^{2}$ pfu ( $80 \%$ mortality) were used (Figure $\left.1 \mathrm{~A}\right)$. After infection, the mice gradually developed anorexia, asthenia and lost weight. From the 6th to the 8th day

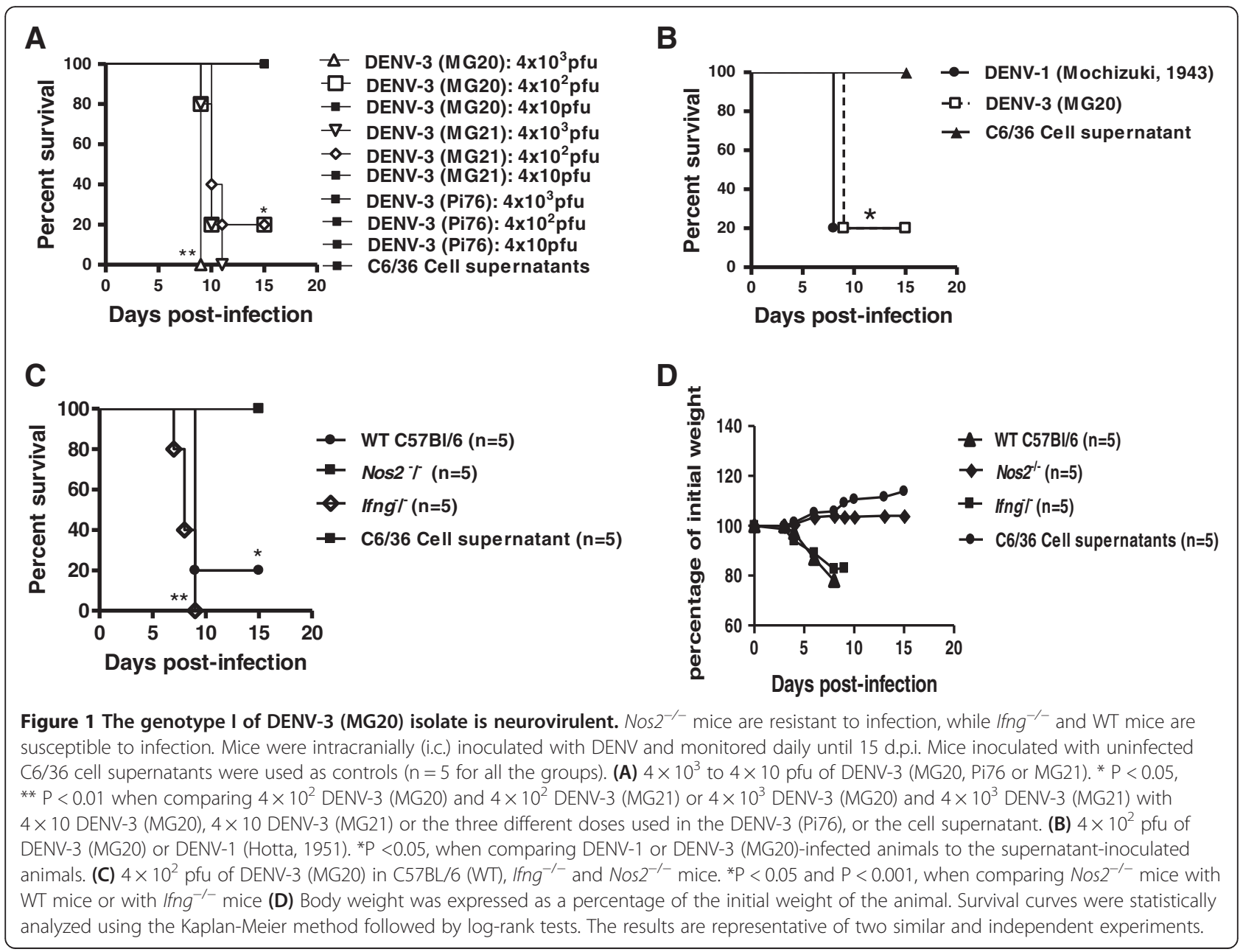


after infection (d.p.i.), $80 \%$ of the mice that were infected with $4 \times 10^{2}$ pfu of DENV-3 genotype I presented ruffled fur, hunched postures and loss of balance followed by paralysis. Most of these mice died 12-24 hours after the onset of paralysis, which was approximately the 10th d.p.i. Mice that were infected with DENV serotypes 1, 2, or 4, with DENV-3 genotype III, or the C6/36 cell supernatant showed no clinical signs or mortality (Figure 1A). The results demonstrate a significant difference $(\mathrm{P}<$ 0.05 ) between the survival curves of mice after infection with $4 \times 10^{2}$ pfu of DENV-3 genotype I (MG20 or MG21) and the survival curves representing the mice infected other DENV types. In mice infected with lethal doses of DENV-3 genotype I, a clear correlation between the viral dose and the time of death was observed. Mice infected with $4 \times 10^{2}$ pfu of DENV-1 Mochizuki, a neurovirulent mouse-adapted strain isolated in 1943 in Japan [22], presented neurological clinical signs and mortality that were similar to those of mice infected with $4 \times 10^{2}$ pfu of DENV-3 genotype I (Figure 1B). Nitric oxide (NO) is synthesized by macrophages after induction of NOS2 by IFN gamma [27,28], and NO has antiviral activities against encephalitic viruses [29]. Thus, Nos2 ${ }^{-/-}$and Ifng ${ }^{-1-}$ mice, both on a C57BL/6 background, were also infected with $4 \times 10^{2}$ pfu of DENV-3 genotype I (MG20) and observed daily for the above cited clinical signs of encephalitis and mortality (Figure 1C). Infected WT, Ifng ${ }^{-1-}$ and Nos $2^{-/-}$mice were monitored for weight loss over a period of 15 days (Figure 1D). Infected WT and Ifng $^{-1-}$ mice presented clinical signs of infection and mortality. WT and Ifng ${ }^{-/}$mice, which were similar to WT mice, exhibited weight loss starting on the $5^{\text {th }}$ d.p.i. (Figure 1D), progressing to lethargy, ruffled fur and hunched postures with posterior paw paralysis and death between the $7^{\text {th }}$ and $10^{\text {th }}$ d.p.i. (Figure $1 C$ ). Only $20 \%$ of the infected WT mice survived. Surprisingly, $100 \%$ of the Nos $2^{-/-}$mice survived infection with DENV-3 genotype I (Figure 1C) without exhibiting any clinical signs of infection or weight loss until the 15th d.p.i. (Figure 1D). There were significant differences in the mortality rates between the infected WT and Nos2 ${ }^{-1-}$ mice $(\mathrm{P}<0.05)$, suggesting a pathological role for NO in DENV-3 genotype I-induced neurological disease. To prove that the infection was successful in the infected Nos $2^{-/-}$mice, a plaque reduction neutralization test $\left(\mathrm{PRNT}_{50}\right)$ was performed using sera from the Nos $2^{-/-}$mice at the 30th d.p.i. The titers obtained in this assay were greater than $100 \mathrm{U} / \mathrm{ml}$.

\section{DENV-3 genotype I (MG20) replicates in the brain, inducing increases in Nos2 and pro-inflammatory cytokine expression levels}

Four WT infected mice per group were euthanized each day for eight days after infection and analyzed to verify the expression levels of virus genes, cytokines and Nos 2 transcripts by real-time PCR. Mice inoculated with uninfected C6/36 cell supernatants were used as controls. Quantitative PCR allowed the detection of viral transcripts in the mouse brains starting on the 2nd d.p.i. and revealed an increasing viral load up to 8 days after infection (Figure 2A). The transcript for cytokine genes $\mathrm{Ccl} 5$, Cxcl10, Ccl3, Ifng, Ifnb, and Tnfa in the mouse brain showed a similar profile, with increased expression levels between the 7th and 8th d.p.i. (Figure 2B-D, F-H). The increased transcript levels were statistically significant for all of the cytokines. The level of the Nos 2 transcript was higher on the 7th and 8th d.p.i. and was significant when compared to mice inoculated with uninfected C6/ 36 cell supernatants (Figure 2E). The presence of virus appears to correlate with increased Nos 2 and cytokine expression in the brain of WT mice between the 7th and 8th d.p.i. (Figure 2).

Nos2 $2^{-1-}$ mice infected with DENV-3 genotype I presented no clinical signs, although high viral titers were found in the brain at the 8th d.p.i.

In contrast with the DENV-3-infected WT mice, $100 \%$ of the Nos $2^{-/-}$mice survived the infection, without exhibiting any clinical signs until the 30th d.p.i. To verify whether the virus replicates in the brains of $\mathrm{Nos}^{-1-}$ mice, these mice were infected with $4 \times 10^{2}$ pfu of DENV-3 genotype I and euthanized on the 8th d.p.i., which corresponds to the peak of viral replication in the WT mouse brains. Mice inoculated with uninfected C6/36 cell supernatants were used as controls. No differences in the viral load were detected in the brains of the WT and Nos2 ${ }^{-1-}$ mice (Figure 3A). These results suggest a neuropathological role for NOS2 in DENV infection. The brains of infected mice that were euthanized on the 8th d.p.i. were analyzed by real-time PCR to verify whether there were different levels of cytokine expression in the infected WT and Nos $2^{-1-}$ mice. The levels of pro-inflammatory cytokine expression increased consistently on the 8th d.p.i. in only the infected WT mice (Figure 3B-E, Figure 3G), with exception of Ifng, which increased in both the WT and in Nos2 ${ }^{-/-}$mice (Figure 3F).

Fewer histopathological alterations were found in Nos $2^{-/-}$ mice infected with DENV-3 genotype I (MG20)

One-half of each infected brain from the mice that were euthanized on the 5th and 8th d.p.i. was formalin fixed for histopathological analysis. Brain sections from the mice that were inoculated with the uninfected C6/36 cell supernatant did not display any pathological changes at any time post-infection (Figure 4A and B). Histological analysis of the brains that were excised on the 5th d.p.i. from WT mice that were infected with DENV-3 genotype I revealed the preservation of nervous tissue with hyperemia, perivascular edema, and a sparse inflammatory infiltrate 


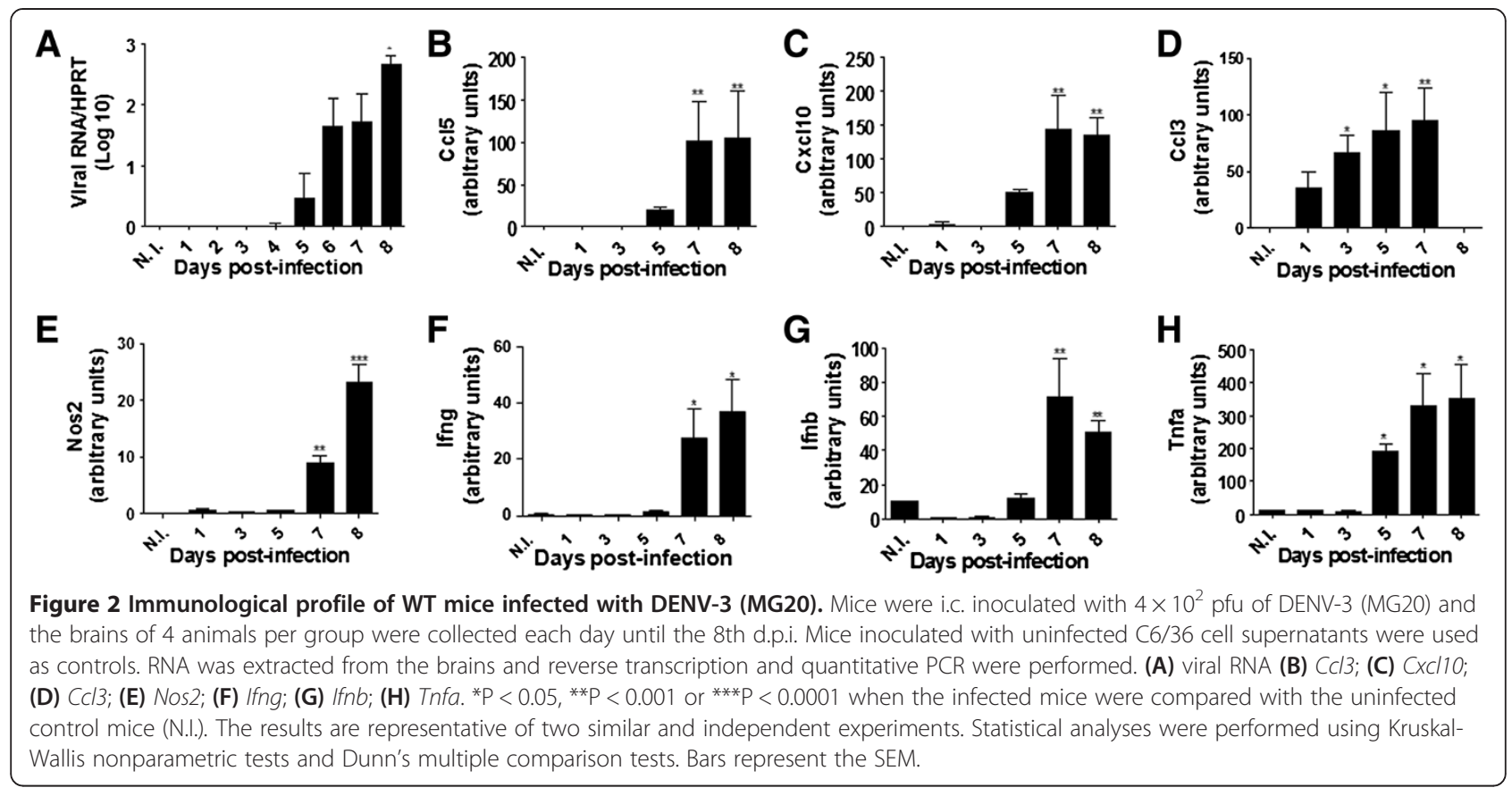

that adhered to the vessel walls (Figure 4C and D). Few inflammatory foci containing mononuclear cells could be detected in the meninges without involvement of the subjacent parenchyma. The histological analysis of brains from DENV-3-infected Nos $2^{-1-}$ mice on the 5th d.p.i. did not differ from the brains of infected WT mice at the same time point (Figure $4 \mathrm{G}$ and $\mathrm{H}$ ). At 8 d.p.i., the brains from DENV-3-infected WT mice exhibited diffuse and intense inflammation and edema of the nervous tissue, vessels and meninges (Figure $4 \mathrm{E}$ and F). Meningitis was characterized by several large inflammatory foci containing mononuclear and polymorphonuclear cells. In the parenchyma, intense vascular alterations, intracellular and pericellular edema, and degenerative changes in neurons and glial cells could be observed, although the inflammatory foci were rare and discrete. Vacuoles in the white and gray matter, irregular areas of necrosis, hemorrhage and recent thrombosis could be detected throughout the

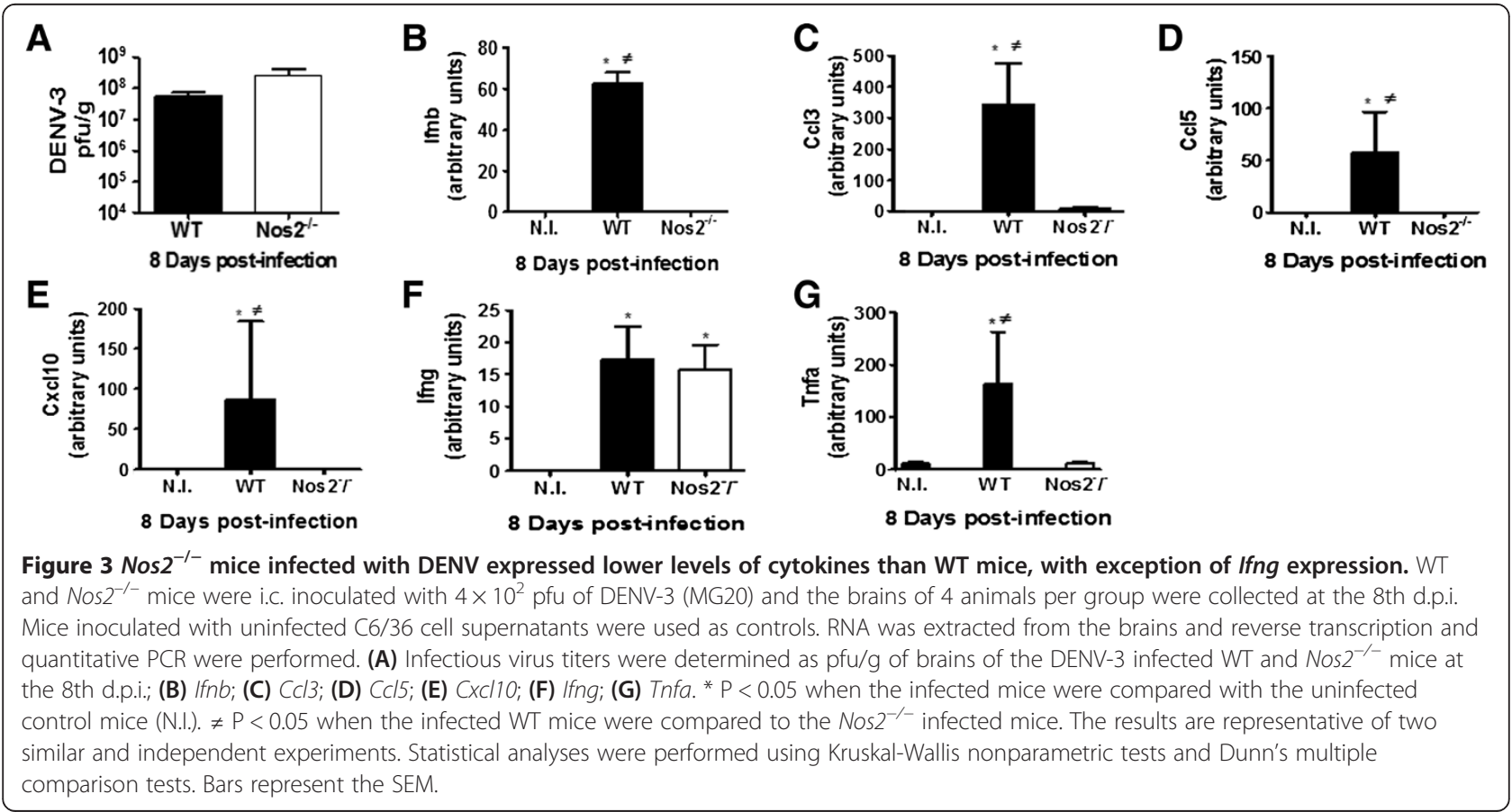




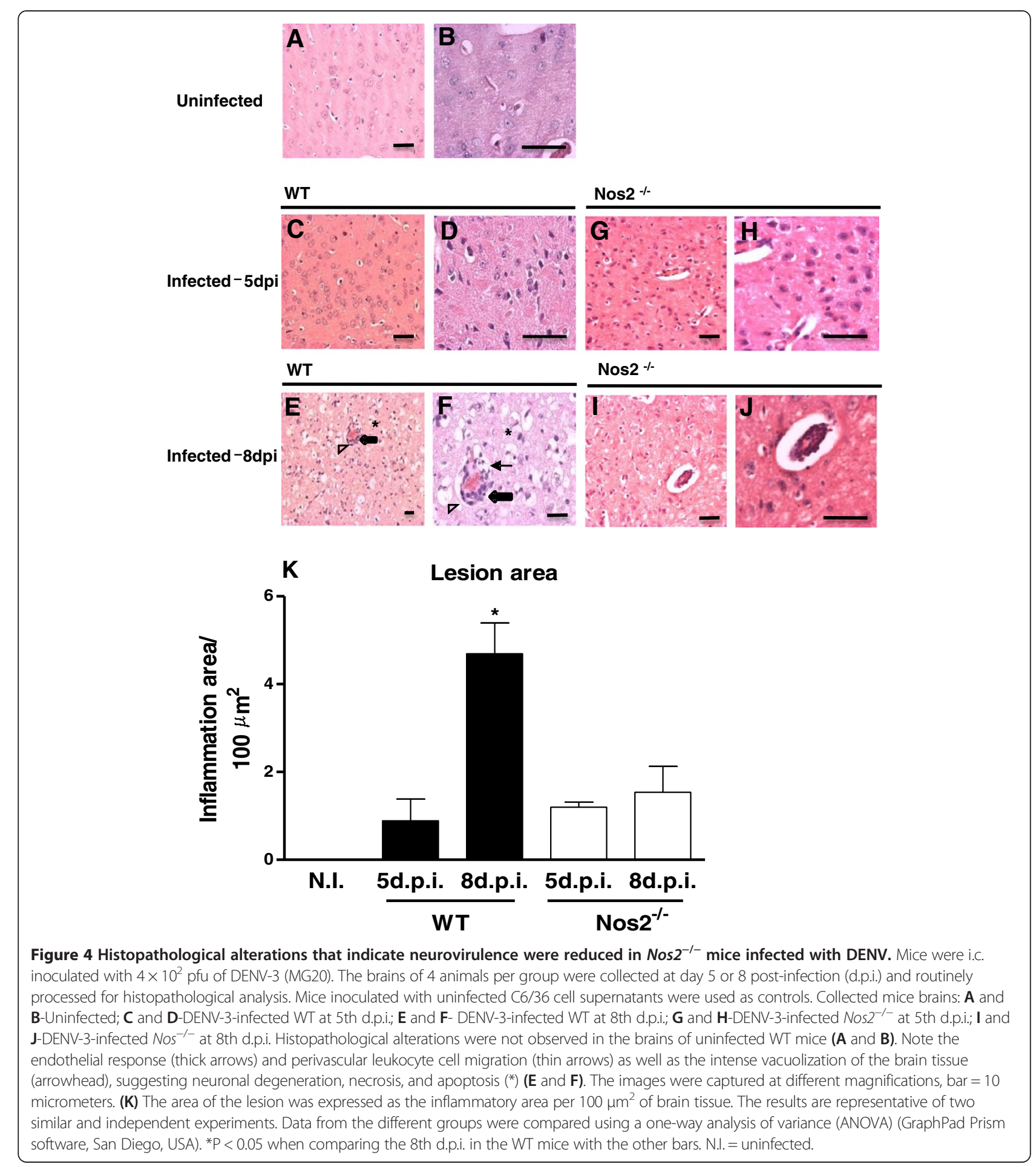

brain. At the same time point, the brains of DENV-3 -infected $N o s 2^{-/-}$mice did not present the histopathological alterations that were observed in the brains from infected WT mice (Figure 4I and J). The infected Nos $2^{-/-}$ brain parenchyma exhibited few isolated necrotic or apoptotic areas, discrete perivascular inflammatory infiltrates, edema and vascular alterations.
Increased levels of IFN gamma and NOS2 in the brains of infected mice are produced by $\mathrm{CD}^{+} \mathrm{T}$ cells and macrophages, respectively

To study the cell populations and the cytokine expression by the cells in the brains of infected mice, we used flow cytometric analysis. This analysis showed that there were more $\mathrm{CD}^{+} \mathrm{T}$ cells producing IFN gamma in the brains of 
infected WT or Nos2 $2^{-1-}$ mice than in the brains of noninfected WT or Nos2 $2^{-1-}$ mice. There was no difference in the number of $\mathrm{CD}^{+} \mathrm{T}$ cells producing IFN gamma in the brains of infected WT mice compared with the brains of infected Nos2 ${ }^{-1-}$ mice (Figure 5A). Natural killer cells and $\mathrm{CD}^{+} \mathrm{T}$ cells were also present in the brain, but the percentage of these cells producing IFN gamma did not differ between the groups of mice (Figure 5B and $\mathrm{C}$ ). The percentage of macrophages producing NOS2 in infected WT mouse brains was significantly higher than in the brains of non-infected WT mice (Figure 5D).

\section{Discussion}

To date, some unique symptoms of dengue remain poorly explained. Thus, the previous guidelines for the classification of dengue diagnosis as DF, DHF and DSS were recently modified by the World Health Organization to dengue without warning signs, dengue with warning signs and severe dengue [12]. One of the criteria for severe dengue is involvement of the central nervous system (CNS) with impaired consciousness. Several reports exist in the literature of CNS involvement following dengue infection: $4 \%$ of 378 patients suspected of CNS infection [1], 9.5\% of children with viral encephalitis [5], and $48 \%$ of 150 fatal cases including CNS involvement [4] were positive for dengue. In two other reports, 5\% [6] and $13.5 \%$ of total dengue patients [7] were identified as having CNS involvement. However, there are serious difficulties in the study of dengue in animal models that include the immune response and immunopathology of dengue with CNS involvement, generally because unmodified DENV does not infect or cause symptoms in laboratory animals. Mouse models of dengue infection have been extensively explored, but none of these models has reproduced all of the clinical symptoms and manifestations of dengue infection that are observed in humans [30,31]. Cell culture passage and mouse adaptation allows the infection with a virus that mimics human disease in mice $[29,32,33]$. However, the alteration of virulence characteristics of the virus can impair the study of induced pathologies that depend on the viral strain, as is the case with neurovirulence. In the present study, we characterized the fatal neurovirulence of non-mouse-adapted DENV-3 (MG20) genotype I that was delivered by i.c. infection of C57BL/6 (WT) mice. Nos $2^{-1-}$ mice were resistant to this virus. DENV-3 MG20 was originally isolated in 2004 from the serum of a fatal human dengue case in Belo Horizonte (MG, Brazil) that had CNS involvement [19]. Although neurological manifestations have been described in dengue, the disease's true prevalence is unknown due to under-recognition of CNS presentations. Interestingly, the same clinical signs and mortality were observed in the DENV-3 MG20 infection in our study as were observed in DENV-1 Mochizuki-infected mice [22], a classical model of neurovirulence in mice.

In our model, immunocompetent mice had high levels of pro-inflammatory cytokine expression in the brain after infection with DENV-3 (MG20). The cytokine and viral gene transcripts exhibited a similar profile with increased expression levels peaking at the 7 th to 8 th d.p.i. and a concomitant increase in viral replication, paralysis, and neural tissue damage, culminating in death, demonstrating the involvement of the immune system in the pathogenesis after infection with DENV-3 (MG20). Molecules such as IFN gamma and TNF alpha appear to be markers for the different degrees of dengue disease or the dengue prognosis [14,34]. The DENV-3 (MG20)infected $I F N-g^{-1-}$ mice were susceptible to infection and exhibited $100 \%$ mortality, presenting the same clinical signs of infection as the infected WT mice. Microscopic

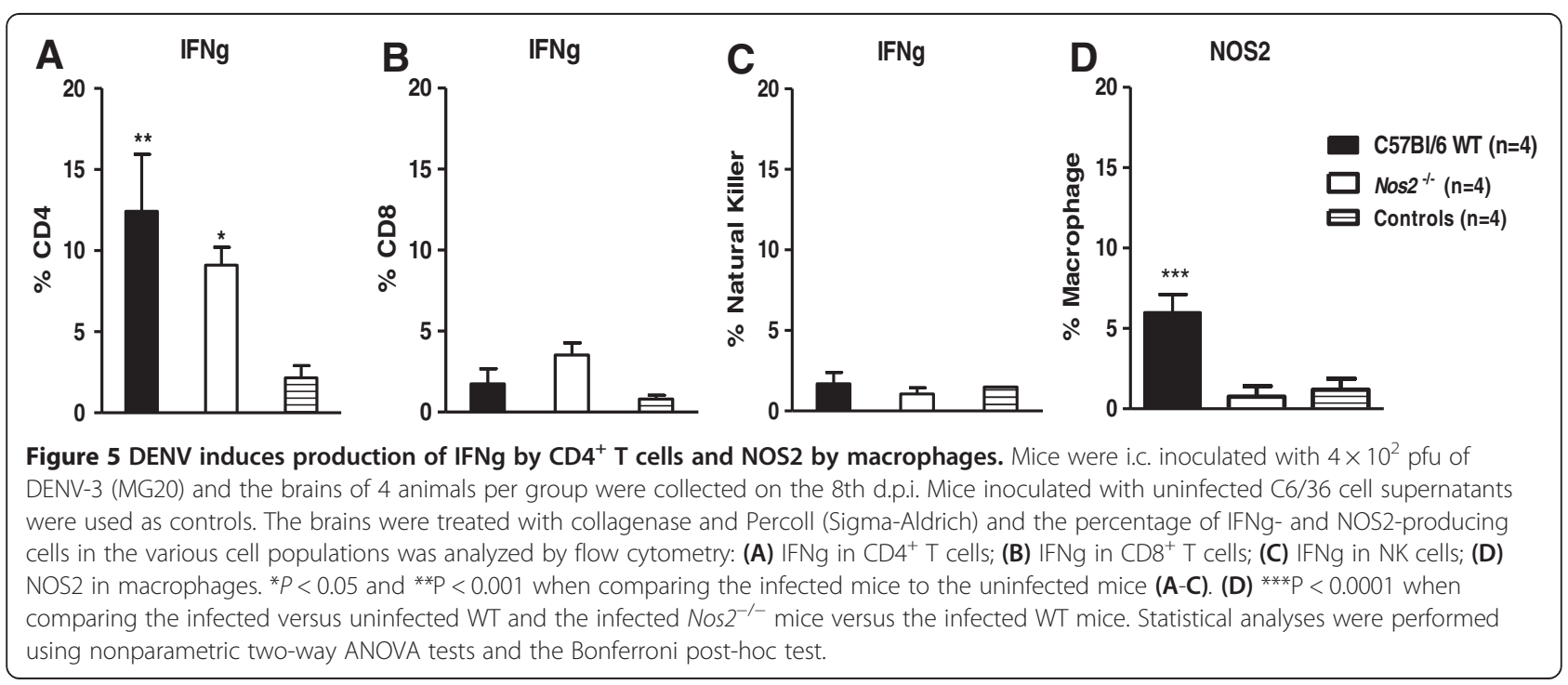


examination of brains from mice that were infected with DENV-3 (MG20) revealed the presence of inflammatory infiltrates and edema in infected WT and $\mathrm{Nos}^{-/-}$mice on the 5th d.p.i. However, on the 8th d.p.i., the brains of the infected WT mice showed an intense endothelial response with perivascular polymorphonuclear cells, mononuclear leukocyte cell migration, meningitis and intense vacuolization that suggested neuronal degeneration, necrosis, and apoptosis. By contrast, the Nos $2^{-/-}$ DENV-infected mice presented only mild histopathological changes in their brains at the 8th d.p.i. As the disease progressed, the infected WT animals appeared to be lethargic and displayed reduced motility. This factor may have resulted in reduced water intake and dehydration of the animals, contributing to the weight loss observed near the moribund stage, and consequently leading to death of the animals. We demonstrated intense vacuolization in the brains of infected mice, suggesting neuronal degeneration, necrosis, and apoptosis. Furthermore, increased Nos 2 expression at the 8th d.p.i. was observed, accompanied by a worsening of the clinical signs and a peak viral load in the brain. Nos 2 is responsible for the cytotoxic action of macrophages and neutrophils, and nitric oxide (NO) has been implicated in neurodegeneration and chronic inflammation in a mouse model of neurotoxicity. When NO production is associated with TNF alpha and IFN gamma in the brain, cerebral damage is caused, which induces an increase in the expression of the genes encoding pro-inflammatory molecules [35]. At optimal doses and when acting on cells of an organ able to regenerate quickly, NO has a protective and regulatory function; however, NO has toxic effects at higher concentrations [36] and when acting on cells of an organ which has difficulty regenerating such as the brain. Our results demonstrated that $100 \%$ of the $\mathrm{Nos}^{-1-}$ mice survived infection with the DENV-3 (MG20) without exhibiting any clinical signs until the 15th d.p.i. Moreover, flow cytometric analysis revealed that $\mathrm{CD} 4^{+} \mathrm{T}$ cells, $\mathrm{CD} 8^{+} \mathrm{T}$ cells and macrophages were present in the brains of infected mice and that the $\mathrm{CD}^{+} \mathrm{T}$ cells were responsible for producing IFN gamma, which most likely induced the production of NOS2 by the WT mouse macrophages in response to DENV infection. Furthermore, the infected $\mathrm{Nos}^{-/-}$ mice displayed no significant increase in cytokine transcripts in their brains with the exception of the Ifng transcript, which was also expressed at a higher level than in uninfected mice. These Nos2-deficient animals exhibited fewer histopathological alterations following infection, confirming the importance of NOS2 in the neuropathogenesis of neurovirulent DENV. By contrast, when mouse-adapted DENV-3 [32] was intraperitoneally injected into the $\mathrm{Nos}^{-/-}$mice, $100 \%$ mortality was observed, indicating that the virus isolate (DENV-3 genotype I or adapted DENV-3) and the route of inoculation (intracranial or intraperitoneal) are distinct variables responsible for these contrasting results. Indeed, each mouse model represents a unique tool to study the various patterns of pathologies caused by DENV.

Thus, i.c. infection of immunocompetent mice with a DENV isolate that causes CNS disease can be used as a tool to study the immune response, immunopathological manifestations, and neurological manifestations of dengue infection that are increasingly being reported in endemic dengue regions.

\section{Conclusions}

In conclusion, DENV-3 genotype I (MG20) induces a virulent infection with CNS involvement and results in death of immunocompetent mice at a low viral dose and without requiring adaptation of the virus to mice. Nitric oxide synthase 2 is deleterious for the host in this experimental mouse infection model. Notably, our data indicate that this mouse model may be a useful tool for studying the immunopathology of dengue in the CNS.

\section{Competing interests}

The authors declare that they have no competing interests.

\section{Authors' contributions}

KPRS, CMAL, RMEA, JASG, JGO, EGK, and MAC conceived of and designed the experiments. KPRS, EGS, ESOR, LBF, CMAL, RMEA, JASG, and GPF performed the experiments. KPRS, JGO, CMAL, RMEA, JASG, EGK, and MAC analyzed the data. RMEA, JASG, EGK, and MAC contributed reagents, materials, and analysis tools. KPRS, CMAL, RMEA, JASG, JGO, EGK, and MAC wrote the paper. All authors read and approved the final manuscript.

\section{Acknowledgements}

This work was supported by the Fundação de Amparo à Pesquisa do Estado de Minas Gerais (FAPEMIG, Brazil, to MAC and EGK), the Conselho Nacional de Desenvolvimento Científico e Tecnológico (CNPq, Brazil, to MAC and EGK), Instituto Nacional de Ciência e Tecnologia de Vacinas/CNPq/FAPEMIG (INCTV/ CNPq/FAPEMIG, Brazil, to MAC), Instituto Nacional de Ciência e Tecnologia Dengue CNPq/FAPEMIG (INCTDengue/CNPq/FAPEMIG, Brazil, to EGK), PRONEXDENGUE, DECIT-Ministério da Saúde (to EGK), Coordenação de Aperfeiçoamento de Pessoal de Nível Superior (CAPES, Brazil), and the Programa Estratégico de Pesquisa em Saúde VI (PAPES)/FIOCRUZ/CNPq (Brazil, to MAC). EGK, MAC and RMEA are Fellows of CNPq. We thank the Program for Technological Development in Tools for Health-PDTIS-FIOCRUZ for the use of its facilities and to João Rodrigues dos Santos for technical support.

\section{Author details}

${ }^{1}$ Universidade Federal de Minas Gerais, Belo Horizonte, Minas Gerais, Brazil. ${ }^{2}$ Universidade Federal do Piauí, Parnaíba, Piauí, Brazil. ${ }^{3}$ Centro de Pesquisas René Rachou, Fundação Oswaldo Cruz, Belo Horizonte, Minas Gerais, Brazil.

Received: 20 May 2013 Accepted: 22 August 2013

Published: 26 August 2013

\section{References}

1. Solomon T, Dung NM, Vaughn DW, Kneen R, Thao LT, Raengsakulrach B, Loan HT, Day NPJ, Farrar J, Myint KSA, Warrell MJ, James WS, Nisalak A, White NJ: Neurological manifestations of dengue infection. Lancet 2000, 355:1053-1059.

2. Balmaseda A, Hammond SN, Pérez L, Tellez Y, Saborío IS, Mercado JC, Rocha J, Pérez MA, Silva S, Rocha C, Harris E: Serotype-specific differences in clinical manifestations of dengue. Am J Trop Med Hyg 2006, 74:449-456.

3. Araújo F, Nogueira R, Araújo MS, Perdigão A, Cavalcanti L, Brilhante R, Rocha M, Vilar DF, Holanda SS, Braga DM, Sidrim J: Dengue in patients with 
central nervous system manifestations, Brazil. Emerg Infect Dis 2012, 18:677-679.

4. Araújo FM, Araújo MS, Nogueira RM, Brilhante RS, Oliveira DN, Rocha MFG, Cordeiro RA, Araújo RMC, Sidrim JJC: Central nervous system involvement in dengue: a study in fatal cases from a dengue endemic area. Neurology 2012, 78:736-742.

5. Tan LT, Phan TQ, Do QH, Nguyen BH, Lam QB, Cam BV, Khanh H, Hien TT, Chau NW, Tram TT, Hien VM, Nga TVT, Shultsz C, Farrar J, Doorn HR, Jong MD: Viral etiology of encephalitis in children in southern Vietnam: results of a one-year prospective descriptive study. PLoS Negl Trop Dis 2010, 4:e854

6. Puccioni-Sohler M, Soares CN, Papaiz-Alvarenga R, Castro MJ, Faria LC, Peralta JM: Neurologic dengue manifestations associated with intrathecal specific immune response. Neurology 2009, 73:1413-1417.

7. Jackson ST, Mullings A, Bennett F, Khan C, Gordon-Strachan G, Rhoden T: Dengue infection in patients presenting with neurological manifestations in a dengue endemic population. West Indian Med J 2008, 57:373-376.

8. García-Rivera EJ, Vorndam V, Rigau-Pérez JG: Use of an enhanced surveillance system for encephalitis and aseptic meningitis for the detection of neurologic manifestations of dengue in Puerto Rico, 2003. PR Health Sci J 2009, 28:114-120.

9. Ferreira ML, Cavalcanti CG, Coelho CA, Mesquita SD: Neurological manifestations of dengue: study of 41 cases. Arq Neuropsiquiatr 2005, 63:488-493.

10. Kankirawatana P, Chokephaibulkit K, Puthavathana P, Yoksan S, Apintanapong S: PonqthapisitV: dengue infection presenting with central nervous system manifestation. J Child Neurol 2000, 5:544-547.

11. Noisakran S, Perng GC: Alternate hypothesis on the pathogenesis of dengue hemorrhagic fever (DHF)/dengue shock syndrome (DSS) in dengue virus infection. Exp Biol Med 2008, 233:401-408.

12. World Health Organization: Dengue guidelines for diagnosis, treatment, prevention and control. Newth edition. Geneva: WHO; 2009.

13. Lin CF, Chiu SC, Hsiao YL, Wan SW, Lei HY, Shiau AL, Liu HS, Yeh TM, Chen SH, Liu CC, Lin YS: Expression of cytokine, chemokine, and adhesion molecules during endothelial cell activation induced by antibodies against dengue virus nonstructural protein 1. J Immuno/ 2005, 174:395-403.

14. Kruif MD, Setiati TE, Mairuhu ATA, Koraka P, Aberson HA, Spek CA, Osterhaus AD, Reitsm PH, Brandjes DP, Soemantri A, van Gorp EC: Differential gene expression changes in children with severe dengue virus infections. PLoS Negl Trop Dis 2008, 2:e215.

15. Bethell DB, Flobbe K, Cao XT, Day NP, Pham TP, Buurman WA, Cardosa MJ, White NJ, Kwiatkowski D: Pathophysiologic and prognostic role of cytokines in dengue hemorrhagic fever. J Infect Dis 1998, 177:778-782.

16. Chin $\mathrm{CH}$, Hofman FM, Kung JT, Lin YD, Wu-Hsieh BA: Both virus and tumor necrosis factor alpha are critical for endothelium damage in a mouse model of dengue virus-induced hemorrhage. J Virol 2007, 81:5518-5526.

17. Yen YT, Chen HC, Lin YD, Shieh CC, Wu-Hsieh BA: Enhancement by tumor necrosis factor alpha of dengue virus-induced endothelial cell production of reactive nitrogen and oxygen species is key to hemorrhage development. J Virol 2008, 82:12312-12324.

18. Chen ST, Lin YL, Huang MT, Wu MF, Cheng SC, Lei HY, Lee C, Chiou T, Wong C, Hsieh S: CLEC5A is critical for dengue-virus-induced lethal disease. Nature 2008, 453:672-676.

19. Figueiredo LB, Cecílio AB, Ferreira GP, Drumond BP, Oliveira JG, Bonjardim CA, Ferreira PCP, Kroon EG: Dengue virus 3 genotype I associated with dengue fever and dengue hemorrhagic fever, Brazil. Emerg Infect Dis 2008, 14:314-316.

20. Vilela APP, Figueiredo LB, Santos JR, Eiras A, Bonjardim CA, Ferreira PCP, Kroon EG: Dengue virus 3 genotype I in aedes aegypti mosquitoes and eggs, Brazil, 2005-2006. Emerg Infect Dis 2010, 16:989-992.

21. Ferreira GP, Figueiredo LB, Coelho LFL, Junior PAS, Cecilio AB, Ferreira PC, Bonjardim CA, Arantes RME, Campos MA, Kroon EG: Dengue virus 3 clinical isolates show different patterns of virulence in experimental mice infection. Microbes Infect 2010, 12:546-554.

22. Hotta S: Experimental studies on dengue I isolation, identification and modification of the virus. J infect Dis 1951, 90:1-9.

23. Osanai CH, Rosa APAT, Tang AT, Amaral RS, Passos ADC, Tauil PL: Surto de dengue em Boa Vista, Roraima: Nota prévia. Rev Inst Med Trop São Paulo 1983, 25:53-54.

24. Russell PK, Nisalak A, Sukhavachana P, Vivona S: A plaque reduction test for dengue virus neutralizing antibodies. J Immunol 1967, 99:285-290.
25. Giulietti A, Overbergh L, Valckx D, Decallonne B, Bouillon R, Mathieu C: An overview of real-time quantitative PCR: applications to quantify cytokine gene expression. Methods 2001, 25:386-401.

26. Pang T, Cardosa MJ, Guzman MG: Of cascades and perfect storms: the immunopathogenesis of dengue haemorrhagic fever-dengue shock syndrome (DHF/DSS). Immunol Cell Biol 2007, 85:43-45.

27. Jiang H, Stewart CA, Leu RW: Tumor-derived factor synergizes with IFNgamma and LPS, IL-2 or TNF-alpha to promote macrophage synthesis of TNF-alpha and TNF receptors for autocrine induction of nitric oxide synthase and enhanced nitric oxide-mediated tumor cytotoxicity. Immunobiology 1995, 192:321-342.

28. Akaike T, Maeda H: Nitric oxide and virus infection. Immunology 2000, 101:300-308.

29. Tan GK, Ng JKW, Trasti SL, Schul W, Yip G, Alonso S: A non mouse-adapted dengue virus strain as a new model of severe dengue infection in AG129 mice. PLoS Negl Trop Dis 2010, 4:e672.

30. Gubler DJ, Suharyono W, Tan R, Abidin M, Sie A: Viraemia in patients with naturally acquired dengue infection. Bull World Health Organ 1981, 59:623-630.

31. Amorim JH, Pereira Bizerra RS, dos Santos Alves RP, Sbrogio-Almeida ME, Levi JE, Capurro ML, Ferreira LCS: A genetic and pathologic study of a DENV2 clinical isolate capable of inducing encephalitis and hematological disturbances in immunocompetent mice. PLOS ONE 2012, 7(9):e44984.

32. Costa W, Fagundes $C T$, Valadão DF, Cisalpino D, Dias AC, Silveira KD, Kangussu LM, Ávila TV, Bonfim MRQ, Bonaventura D, Silva TA, Souza LP, Rachid MA, Vieira LQ, Menezes GB, de Paula AM, Atrasheuskaya A, Ignatyev G, Teixeira MM, Souza DG: A model of DENV-3 infection that recapitulates severe disease and highlights the importance of IFN- $\gamma$ in host resistance to infection. PLoS Negl Trop Dis 2012, 6:e1663.

33. Souza DG, Fagundes CT, Souza LP, Amaral FA, Souza RS, Souza AL, Kroon EG, Sachs D, Cunha FQ, Bukin E, Atrasheuskaya A, Ignatyev AG, Teixeira MM: Essential role of platelet-activating factor receptor in the pathogenesis of dengue virus infection. Proc Natl Acad Sci USA 2009, 106:14138-14143.

34. Bozza FA, Cruz OG, Zagne SMO, Azeredo EL, Nogueira RMR, Assis EF, Bozza PT, Kubelka CF: Multiplex cytokine profile from dengue patients: MIP1 beta and IFN-gamma as predictive factors for severity. BMC Infect Dis 2008, 8:86

35. Blais V, Rivest S: Effects of TNF-a and IFN-g on nitric oxide-induced neurotoxicity in the mouse brain. J Immunol 2004, 172:7043-7052.

36. Chaturvedi UC, Nagar R: Nitric oxide in dengue and dengue haemorrhagic fever: necessity or nuisance? Immunol Med Microbiol 2009, 56:9-24.

doi:10.1186/1743-422X-10-267

Cite this article as: de Souza et al:: Nitric oxide synthase expression correlates with death in an experimental mouse model of dengue with CNS involvement. Virology Journal 2013 10:267.

\section{Submit your next manuscript to BioMed Central and take full advantage of:}

- Convenient online submission

- Thorough peer review

- No space constraints or color figure charges

- Immediate publication on acceptance

- Inclusion in PubMed, CAS, Scopus and Google Scholar

- Research which is freely available for redistribution 